\title{
FUNCTIONAL CAPACITY IN ADOLESCENT IDIOPATHIC SCOLIOSIS DURING THE POSTOPERATIVE PERIOD
}

\author{
CAPACIDADE FUNCIONAL NA ESCOLIOSE IDIOPÁTICA DO ADOLESCENTENO PERÍODO \\ PÓS-OPERATÓRIO

\begin{abstract}
CAPACIDAD FUNCIONAL EN LA ESCOLIOSIS IDIOPÁTICA DEL ADOLESCENTE EN EL PERÍODO POSTOPERATORIO
\end{abstract}

Original Article

ARTIGO ORIGINAL

Artículo Original

\author{
Geferson da Silva Araujo \\ (Physiotherapist) \\ Bruna Marques de Almeida Saraiva \\ (Physiotherapist) \\ Evandro Fornias Sperandio \\ (Physiotherapist) \\ Marcos de Toledo Filho' \\ (Physiotherapist) \\ Jaqueline de Mesquita Freira \\ (Physiotherapist) \\ Alberto Ofenhejm Gotfryd ${ }^{2}$ \\ (Physician) \\ Liria Yuri Yamauchi \\ (Physiotherapist) \\ Victor Zuniga Dourado \\ (Physiotherapist) \\ Milena Carlos Vidotto \\ (Physiotherapist)

\begin{abstract}
1. Universidade Federal de São Paulo (UNIFESP), Department of Human Movement Sciences, Laboratório de Epidemiologia e Movimento Humano (EPIMOV), Santos,

SP, Brazil.

2. Hospital Israelita Albert Einstein, Department of Orthopedics,

São Paulo, SP, Brazil.
\end{abstract}

\section{Correspondence}

Bruna Marques de Almeida Saraiva. Rua Silva Jardim, 136, VI. Mathias, Santos, SP, Brazil. 11015-020. brunalmeidam@gmail.com

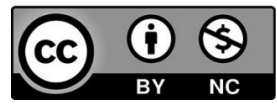

\begin{abstract}
Introduction: Patients with Adolescent Idiopathic Scoliosis (AIS) show reduced exercise capacity during the Incremental Shuttle Walk Test (ISWT). However, we not know how patients behave in the late postoperative (LPO) period. Objective: The aim of this study was to evaluate the ISWT distance (ISWTD) and physiological responses during ISWT in AIS patients during the LPO period. Methods: We included 22 patients with AIS in the LPO period (SG) and 21 adolescents in the Control Group (CG). We assessed pulmonary function ( $F V\left(\right.$ and $\mathrm{FEV}_{1}$ ). During ISWT, a gas analyzer was used to assess peak oxygen $\left(\mathrm{VO}_{2}\right)$ and submaximal relations: Oxygen Uptake Efficiency Slope (OUES) and the breathing pattern ( $\triangle \mathrm{VTT} / \Delta \mathrm{InVE})$. Results: Significantly lower values were observed in SG: VO 2 (22 \pm 5 Vs. $27 \pm 4$ ), ISWTD (567 \pm 94 vs.604 \pm 86$)$, FVC (2.70 \pm 0.47 vs. $3.33 \pm 0.52)$ and FEV $(2.41 \pm 0.46$ vs. $2.84 \pm 0.52)$. There were significant correlations between ISWTD and $\mathrm{VO}_{2} / \mathrm{Kg}(r=0.80)$; between OUES and $\triangle \mathrm{VT} / \Delta \mathrm{InVE}(r=0.65)$; and between the main thoracic curve with $\mathrm{VO}_{2} / \mathrm{Kg}(\mathrm{r}=-0.61)$. Conclusion: AIS patients in the LPO period have significantly reduced exercise capacity associated with reduced lung function, residual spinal curve and cardiovascular deconditioning. Level of Evidence III; Prognostic Studies - Investigation of the effect of characteristic of a patient on the outcome of the disease.
\end{abstract}

Keywords: Adolescents; Exercise testing; Oxygen consumption; Physical fitness.

\section{RESUMO}

Introdução: Pacientes com escoliose idiopática do adolescente (EIA) têm capacidade de exercício reduzida durante o Incremental Shuttle Walk Test (ISWT). No entanto, não sabemos como os pacientes se comportam no período pós-operatório tardio (POT). Objetivo: O objetivo deste estudo foi avaliar a distância do ISWT (ISWTD) eas respostas fisiológicas durante o teste em pacientes com EIA no período POT. Métodos: Foram incluídos 22 pacientes com EIA no período POT (GCi) e 21 adolescentes no Grupo Controle (GCo). Avaliamos a função pulmonar (CVFe VEF1). Durante o ISWT, foi utilizado um analisador de gases para avaliar o pico de oxigênio (VO2) e as relações submáximas: eficiência da captação de oxigênio (OUES) e o padrão de respiração ( $\triangle V C / \Delta / n V E)$. Resultados: Valores significativos mais baixos foram observados no GCi:VO2 (22 \pm 5 vs. $27 \pm 4$ ), ISWTD (567 \pm 94 vs. $604 \pm 86), \operatorname{CVF}(2,70 \pm 0,47$ vs. 3,33 $\pm 0,52)$ e VEF1 $(2,41 \pm 0,46$ vs. 2,84 $\pm 0,52)$. Houve correlações significativas entre ISWTD eVO2/Kg ( $r=0,80)$; entre OUES e $\triangle V C / \Delta I n V E(r=0,65)$ e entre a curva torácica principal com VO2/Kg $(r=-0,61)$. Conclusão: Os pacientes com EIA no período POT tiveram redução significante da capacidade de exercício associada à função pulmonar reduzida, curva residual na coluna vertebral e descondicionamento cardiovascular. Nível de Evidência III; Estudos Prognósticos - Investigação do efeito de característica de um paciente sobre o desfecho da doença.

Descritores: Adolescentes; Testes de exercício físico; Consumo de oxigênio; Aptidão física.

\section{RESUMEN}

Introducción:Pacientes con escoliosis idiopática del adolescente (EIA) tienen capacidad deejercicio reducida duranteel Incremental Shuttle Walk Test (ISWT). Sin embargo, no sabemos cómo los pacientes se comportan en el período postoperatorio tardio (POT). Objetivo: El objetivo de esteestudio fue evaluar la distancia del ISWT (ISWTD) y las respuestas fisiológicas durantel a prueba en pacientes con EIA en el período POT. Métodos: Se incluyeron 22 pacientes con EIA en el período POT (GQ) y 21 adolescentes en el grupo control (GC). Seevaluó lafunción pulmonar (CVFyVEF1). DuranteelISWT, seutilizó un analizador de gases para evaluarel pico de oxígeno (VO2) y las relaciones submáximas: eficiencia de la captación de oxígeno (OUES) yel patrón respiratorio ( $\triangle V C / \Delta / n V E)$. Resultados: Seobservaron valores signi-

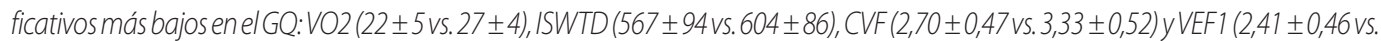
2,84 $\pm 0,52)$. Hubo correlaciones significativas entreISWTD y VO2/Kg $(r=0,80)$ entre OUES y $\triangle V C / \triangle \operatorname{lnVE}(r=0,65)$ yentre la curva torácica principal con VO2/Kg ( $r=-0,61)$. Conclusión: Ios pacientes con EIA en el período POT tuvieron reducción significativa de la capacidad de ejercicio asociada a la función pulmonar reducida, l curva residual de la columnavertebraly la falta de condicionamiento cardiovascular. Nivel de evidencia III; Estudios pronósticos - Investigación del efecto de característica de un paciente sobre el desenlace de la enfermedad.

Descriptores: Adolescentes; Test de esfuerzo físico; Consumo de oxígeno; Aptitud física. 


\section{INTRODUCTION}

The adolescent idiopathic scoliosis (AIS) represents $80 \%$ of all idiopathic scoliosis, with a higher prevalence in women, affecting especially the age group between 10 and 18 years. ${ }^{1}$ Surgical treatment is indicated in spinal curvatures greater than $45^{\circ 1}$ and aims to prevent disease progression and correct deformities ${ }^{2}$ that could compromise ventilatory mechanics and exercise capacity. ${ }^{3}$

Individuals with AIS exhibit lower exercise tolerance. This has already been demonstrated with a significant reduction in oxygen consumption $\left(\mathrm{VO}_{2}\right)$ in Cardiopulmonary Exercise Testing (CPET). ${ }^{4-6}$ Few studys used the Incremental Shuttle Walking Test (ISWT) to evaluate exercise limitation in this population, ${ }^{3,7,8}$ but only in patients during the preoperative period. The ISWT is a simple walking test, which shows good reproducibility, no need to use specific ergometer ${ }^{9,10}$ and it can be done with good tolerance and safety in children and adolescents. ${ }^{11}$ The Incremental Shuttle Walk Distance (ISWD) shows consistent correlation with $\mathrm{VO}_{2}$ peak obtained in the CPET. ${ }^{12}$

Based in the literature and in the absence of consensus on exercise tolerance in CPET after surgery, ${ }^{4}$ we hypothesized that there is a significant impairment in functional exercise capacity in AIS patients at late postoperative (LPO) period. The aim of this study was to evaluate the ISWD and physiological responses during ISWT in AIS patients at the LPO and to assess the postoperative spinal curvature, respiratory muscle strength, pulmonary function and its correlation with the physiological variables.

\section{METHODS}

This is a cross-sectional study, with AIS patients in the LPO period and healthy individuals. All participants and their legal representatives signed the consent form and free and informed consent. The Ethics Committee approved this study ( $\left.n^{\circ} 1349351\right)$.

Patients were screened voluntarily during the Orthopedics appointment in a local Hospital. During the screening were collected the angle values of postoperative curvatures using the Cobb method. Proximal thoracic Cobb angle (CobbPT), main thoracic Cobb angle (CobbMT) and lumbar Cobb angle (CobbL) were recorded, also were recorded the number of fixed vertebrae during surgery.

Female patients diagnosed with AIS in LPO period of arthrodesis with posterior approach were included in the scoliosis group (SG). It was considered LPO the minimum of 18 and maximum of 36 months after surgery. Were excluded from this study those patients with a previous or current history of heart, lung or neuromuscular diseases and patients who for some reason failed to perform the evaluations proposed. Physically active patients were also excluded. ${ }^{13}$

The control group (CG) was matched to the SG. Exclusion criteria were the same described for SG, but were also excluded those individuals with spinal deformity or other important postural changes assessed by the Adams test and postural assessment. ${ }^{14}$

The anthropometric data was assessmed, for weight measurement was used a scale with $0.1 \mathrm{~kg}$ precision and for height was used a stadiometer to the nearest $0.5 \mathrm{~cm}$. Body mass index (BMI) was calculated (weight (kg)/ height ${ }^{2}(\mathrm{~m})$ ).

\section{Respiratory Assessment}

Spirometry was performed with a portable spirometer (microQuarck; Cosmed, Pavonadi Albano, Italy) according to BSTA recommendations. ${ }^{15}$ Forced vital capacity (FVC), forced expiratory volume in the first second $\left(\mathrm{FEV}_{1}\right)$ and the $\mathrm{FEV}_{1} / \mathrm{FVC}$ ratio in absolute and percentage of predicted values for the Brazilian population ${ }^{16}$ were considered.

\section{Incremental Shuttle Walk Test (ISWT)}

The ISWT was performed according to the recommendations. ${ }^{9}$
Heart rate, oxygen saturation, blood pressure and perceived dyspnea and fatigue of the lower limbs (Borg scale) were assessed before and immediately after ISWT. Two tests were conducted with 30 min intervals between them. The walked distance (ISWD) of the second test was considered for the analysis.

During the second ISWT expired gasses were collected and analyzed in portable equipment with telemetry module (K4b2, Cosmed, Pavonadi Albano, Italy). It was used a facial mask with minimal dead space $(50 \mathrm{~mL})$. The gas analyzer was accommodated to the trunk of the participants allowing free movement without discomfort. Calibrations were performed following the manufacturer's recommendations.

Oxygen uptake $\left(\mathrm{VO}_{2}\right), \mathrm{VCO}_{2}$, tidal volume (VT), respiratory rate (RR), heart rate $(H R)$, and other variables obtained by calculations based on these variables were recorded breath by breath. The ventilatory reserve (VR) was analyzed and represented by the difference between maximum voluntary ventilation and minute ventilation (MVV-VE). Data were filtered every 15 seconds for analysis and all measurements were obtained at the test peak. Additionally, based on the baseline linear regression value (intercept) and the rate of change (slope), the following submaximal relations were determined: $\triangle \mathrm{HR} / \Delta \mathrm{VO}_{2}, \Delta \mathrm{VE} / \triangle \mathrm{VCO}_{2}$ and $\Delta \mathrm{VT} / \Delta \mathrm{VE}$ linearized (ie, $\Delta V T / \Delta I n V E)$. These relations were obtained by linear regressions and respectively represent the cardiovascular and respiratory efficiency and breathing pattern during the test. An additional variable was used during the incremental test to check oxygen uptake efficiency slope (OUES), expressed as the ratio $\Delta \mathrm{VO}_{2} / \Delta \log V E$

\section{Statistical analysis}

The sample size was calculated taking into consideration the minimum clinically significant differences in peak VO2 during ISWT. In a previous study with healthy participant, peak $\mathrm{VO}_{2}$ during ISWT presented a standard deviation of $609 \mathrm{~mL} / \mathrm{min}$, with a reduction of $605 \mathrm{~mL} / \mathrm{min}$ representing the lower limit of normal. ${ }^{17} \mathrm{We}$, therefore, considered the reduction of more than $605 \mathrm{~mL} / \mathrm{min}$ as clinically significant for peak $\mathrm{VO}_{2}$ related to ISWT. With the standardized effect size around one, probability alpha error at 0.05 and beta of 0.20 , we obtained the number of at least 16 participants in each research group.

Data were analyzed descriptively and are presented according to the distribution of the studied variables. The normality of variables was investigated by Shapiro-Wilk test. To compare the means or medians of variables between groups we used the unpaired T-test or Mann-Whitney test. The correlations were assessed by Pearson or Spearman coefficients and linear regressions were performed. The probability of alpha error was set at 5\% for all analyzes.

\section{RESULTS}

We evaluated 56 participants, four patients were excluded from SG for not completing all assessments proposed and nine were excluded from CG because they have postural abnormalities detected on screening. The final sample consisted of 43 individuals, of which 22 (51.16\%) were allocated to SG. AIS patients had on average $24 \pm 9$ months of postoperative and the number of fixed vertebrae was 8.7-11 No significant differences were observed between groups regarding anthropometric characteristics (Table 1).

The absolute and predicted values of FVC and FEV 1 were, on average, significantly lower in the SG (Table 2).

The ISWD values were significantly lower in the SG compared to the CG, both in the first and in the second test. Patients with scoliosis walked greater distance in the second test ( $p$ 0.041). Data regarding the ISWT and physiological responses are described in Table 3. Among the submaximal relations, only $\triangle V T / \triangle I n V E$ and OUES presented statistical difference between groups, showing lower values 
Table 1. Demographic, anthropometric and Cobb angles values.

\begin{tabular}{c|c|c|c}
\hline Variables & SG & CG & P \\
\hline $\mathrm{N}(\%)$ & $22(51 \%)$ & $21(49 \%)$ & \\
\hline Age, $\mathrm{yr}$ & $15 \pm 2$ & $15 \pm 3$ & 0,768 \\
\hline Weight, $\mathrm{kg}$ & $49[45-55]$ & $52[45-60]$ & 0,337 \\
\hline Height, $\mathrm{m}$ & $1,62 \pm 0,08$ & $1,61 \pm 0,08$ & 0,726 \\
\hline BMl, kg/m2 & $19[16-20]$ & $20[18-22]$ & 0,264 \\
\hline CobbPT & $9[5-17]$ & & \\
\hline CobbMT & $14 \pm 6$ & & \\
\hline CobbL & $12 \pm 8$ & & \\
\hline
\end{tabular}

SG - Scoliosis group; CG - control group; CobbPT: proximal thoracic Cobb angle; CobbMT: main thoracic Cobb angle; CobbL: lumbar Cobb angle.

Table 2. Respiratory pressures and pulmonary function in AIS patients at the late postoperative period and healthy adolescents.

\begin{tabular}{c|c|c|c}
\hline Variables & SG & CG & p \\
\hline \multicolumn{4}{c}{ Respiratory pressures } \\
\hline MIP, $\mathrm{cmH} 20$ & $66 \pm 19$ & $75 \pm 21$ & 0,179 \\
\hline MEP, $\mathrm{cmH} 20$ & $62 \pm 22$ & $71 \pm 20$ & 0,206 \\
\hline \multicolumn{4}{c}{ Spirometry } \\
\hline FVC, L & $2,70 \pm 0,47$ & $3,33 \pm 0,52$ & $<0,001$ \\
\hline FVC, \% of predicted & $86 \pm 13$ & $105 \pm 15$ & $<0,001$ \\
\hline FEV, L & $2,41 \pm 0,46$ & $2,84 \pm 0,52$ & 0,007 \\
\hline FEV $\%$ of predicted & $83 \pm 14$ & $99 \pm 16$ & 0,002 \\
\hline FEV, FVC, \% & $89 \pm 10$ & $85 \pm 8$ & 0,150 \\
\hline
\end{tabular}

SG - Scoliosis group; CG - control group: MIP. maximal inspiratory pressure MEP. maximal expiratory pressure FVC: forced vital capacity; FEV $_{1}$ : forced expiratory in first second.

Table 3. Values of means and standard deviations or medians and interquartile ranges of the metabolic, ventilatory responses, cardiovascular and submaximal relations during ISWT.

\begin{tabular}{|c|c|c|c|}
\hline Variables & SG & CG & $p$ \\
\hline \multicolumn{4}{|c|}{ ISWT } \\
\hline $1^{\text {st }}$ ISWD (m) & $419 \pm 92$ & $444 \pm 81$ & $<0,001$ \\
\hline $2^{\text {nd }}$ ISWD (m) & $567 \pm 94$ & $604 \pm 86$ & $<0,001$ \\
\hline \multicolumn{4}{|c|}{ Metabolic responses } \\
\hline $\mathrm{VO}_{2}, \mathrm{ml} / \mathrm{min}$ & $1108 \pm 243$ & $1474 \pm 315$ & $<0,001$ \\
\hline $\mathrm{VO}_{2}, \mathrm{ml} / \mathrm{kg} / \mathrm{min}$ & $22 \pm 5$ & $27 \pm 4$ & 0,001 \\
\hline $\mathrm{VCO}_{2}, \mathrm{ml} / \mathrm{min}$ & $1095 \pm 318$ & $1610 \pm 326$ & $<0,001$ \\
\hline $\mathrm{R}, \mathrm{ml} / \mathrm{min}$ & $1,05[0,95-1,12]$ & $1,19[1,08-1,35]$ & 0,002 \\
\hline \multicolumn{4}{|c|}{ Ventilatory responses } \\
\hline RR (ipm) & $42[35-58]$ & $47[40-56]$ & 0,136 \\
\hline $\mathrm{VT}(\mathrm{L})$ & $0,91[0,71-1,21]$ & $1,34[1,09-1,58]$ & 0,001 \\
\hline $\mathrm{VE}(\mathrm{L} / \mathrm{min})$ & $37 \pm 11$ & $54 \pm 11$ & $<0,001$ \\
\hline $\mathrm{VE} / \mathrm{NO}_{2}$ & $34[33-40]$ & $41[35-51]$ & 0,075 \\
\hline $\mathrm{VE} / \mathrm{NCO}_{2}$ & $39[38-46]$ & $40[37-43]$ & 0,940 \\
\hline VR (\%) & $75 \pm 5$ & $67 \pm 10$ & 0,008 \\
\hline \multicolumn{4}{|c|}{ Cardiovascular responses } \\
\hline $\mathrm{HR}(\mathrm{bpm})$ & $149 \pm 29$ & $185 \pm 12$ & $<0,001$ \\
\hline $\mathrm{PuO}_{2}(\mathrm{ml} / \mathrm{min} / \mathrm{bpm})$ & $7,95[6,62-12,52]$ & $8,20[7,20-9,20]$ & 0,869 \\
\hline \multicolumn{4}{|c|}{ Submaximal relations } \\
\hline$\Delta \mathrm{HR} / \Delta \mathrm{VO}_{2}(\mathrm{bpm} / \mathrm{L} / \mathrm{min})$ & $63 \pm 20$ & $69 \pm 30$ & 0,498 \\
\hline$\Delta \mathrm{VE} / \Delta \mathrm{VCO}_{2}(\mathrm{~L} / \mathrm{min})$ & $29 \pm 4$ & $29 \pm 5$ & 0,818 \\
\hline$\Delta \mathrm{VT} / \Delta \operatorname{lnVE}$ & $0,33 \pm 0,11$ & $0,43 \pm 0,14$ & 0,029 \\
\hline OUES (ml/min)/(L/min) & $1491 \pm 220$ & $1778 \pm 452$ & 0,022 \\
\hline \multicolumn{4}{|c|}{ Borg scale } \\
\hline Dyspnea & $4[2-5]$ & $5[3-8]$ & 0,144 \\
\hline Lower limbs fatigue & $4[3-7]$ & $5[3-8]$ & 0,399 \\
\hline
\end{tabular}

SG - Scoliosis group; CG - control group; ISWD: Incremental Shuttle Walking Test distance; VO ${ }_{2}$ : oxygen uptake $\mathrm{VCO}_{2}$ : carbon dioxide production, $\mathrm{R}$ : rate of gas Exchange, RR: respiratory rate, $\mathrm{VT}$ : tidal volume, VE: minute ventilation, $\mathrm{VE} / \mathrm{NO}_{2}$ : respiratory equivalent of oxygen, $\mathrm{VE} / \mathrm{NCO}_{2}$ : respiratory equivalent carbon dioxide, OUES $\left(\triangle \mathrm{VO}_{2} /\right.$ $\Delta$ logVE): oxygen uptake efficiency slope, $\mathrm{VR}$ : ventilatory reserve, $\mathrm{HR}$ : heart rate, $\mathrm{PuO}_{2}$ : oxygen pulse, $\triangle \mathrm{HR} / \Delta \mathrm{VO}_{2}$ : cardiovascular efficiency; $\Delta \mathrm{VE} / \Delta \mathrm{V} \mathrm{CO}_{2}$ : ventilatory efficiency, $\triangle \mathrm{VC} / \Delta \mathrm{InVE}$ : ventilatory pattern. in the SG. Figure 3 presents a typical example of a worse respiratory pattern and OUES in the SG.

Strong correlations were observed between ISWD with $\mathrm{VO}_{2}$ and $\mathrm{VO}_{2} / \mathrm{kg}$ (Figure 1). Moderate correlation was observed between ISWD and CobbMT $(r=-.47 ; p=.116)$ and HR $(r=.44 ; p=.076)$. Moderate correlations were observed between $\mathrm{VO}_{2}$ and OUES $(r=.67 ; p=.001)$, FEV1 $(r=0.48 ; p=.035)$ and the number of fixed vertebrae $(r=.43$; $p=.16)$. In addition, $\mathrm{VO}_{2}$ and OUES showed moderate correlations with $\triangle V C / \triangle I n V E$ (Figure 2). Moderate correlations were observed between $\mathrm{VO}_{2}$ and $\mathrm{VR}(r=-.46 ; p=.046)$.

Regarding the postoperative residual scoliotic curve and the physiological variables studied, moderate correlations were observed between CobbMT and $\mathrm{VO}_{2} / \mathrm{kg}(\mathrm{r}=-.61 ; p=.035)$ and $\mathrm{HR}(\mathrm{r}=-.40 ; p=.222)$.

\section{DISCUSSION}

Data presented in this study indicate reduced exercise capacity in AIS patients in the late postoperative period compared to healthy participants. Moreover, we observed significant associations of exercise capacity with lung function, Cobb angle and ventilatory pattern during exercise.

All scoliosis patients in this study had a mild postoperative spinal curvature with angles lower than $20^{\circ} .1$ We observed correlation between $\mathrm{VO}_{2}$ and CobbMT and the number of fixed vertebrae in the surgical procedure. These data suggest that the surgical technique may influence the exercise capacity in AIS patients at LPO.

It is known that the walked distance in the six-minute walk test ${ }^{18}$ and the ISWD ${ }^{3,7}$ are reduced in the AIS patients in the preoperative period, but data on LPO period were not found in the literature. In the present study, we observed significantly lower walked distances in the SG, with a difference compared to CG of $25 \mathrm{~m}$ in the first test and $37 \mathrm{~m}$ in the second. These differences were lower than the minimum clinically important difference (MCID), known as $47.5 \mathrm{~m}$ for the ISWT in adults with chronic obstructive pulmonary disease, ${ }^{19}$ but sufficient to observe a lower $\mathrm{VO}_{2}$ at $\mathrm{SG}$, both in the first and second test. Considering that the R values obtained in our study (>0.95) indicate high-intensity exercise performance ${ }^{20}$ and that the ISWD and $\mathrm{VO}_{2}$ values were lower in the SG, we can highlight the presence of lower exercise capacity in this study group.

It might be noted that the difference in ISWD between the first and the second test in scoliosis patients was 148 meters and the control group was 160 meters. These differences reinforce the need for a second test in this population, due to the important learning effect observed.

In a previous studie was observed in AIS patients at the preoperative period ISWD of 69 meters less than that observed in our study. ${ }^{7}$ The authors also observed higher $\mathrm{VO}_{2}(1247 \pm 450 \mathrm{ml} / \mathrm{min})$ and lower ISWD (498 $\pm 144 \mathrm{~m})$ when compared to our study. The patients in the LPO period in the present study presented lower $\mathrm{VO}_{2}$ obtained in a higher ISWD. Although they are not the same individuals, these data suggest a better exercise capacity in AIS patients in LPO compared to patients in the preoperative period.

We observed lower $\mathrm{VO}_{2}$ and $\mathrm{VO}_{2} / \mathrm{Kg}$ values in $\mathrm{SG}$ compared to the CG with a strong correlation between $\mathrm{VO}_{2}$ and ISWD. Considering that $\mathrm{VO}_{2}$ is the best aerobic capacity index and the gold standard to determine physical fitness in $\mathrm{CPET}^{21}$ and whereas evidence that the correlation between ISWD and $\mathrm{VO}_{2}$ at the end of ISWT $(r=0.81)$ is similar to that observed in CPET performed on a treadmill $(r=0.88)^{22}$, our data underline the presence of physical deconditioning in SG. It is important to highlight the reduced OUES values in SG and its correlation with $\mathrm{VO}_{2}$ in this study, indicating a reduction in $\mathrm{O}_{2}$ uptake and utilization, and reduced exercise capacity. It is known that OUES is an 


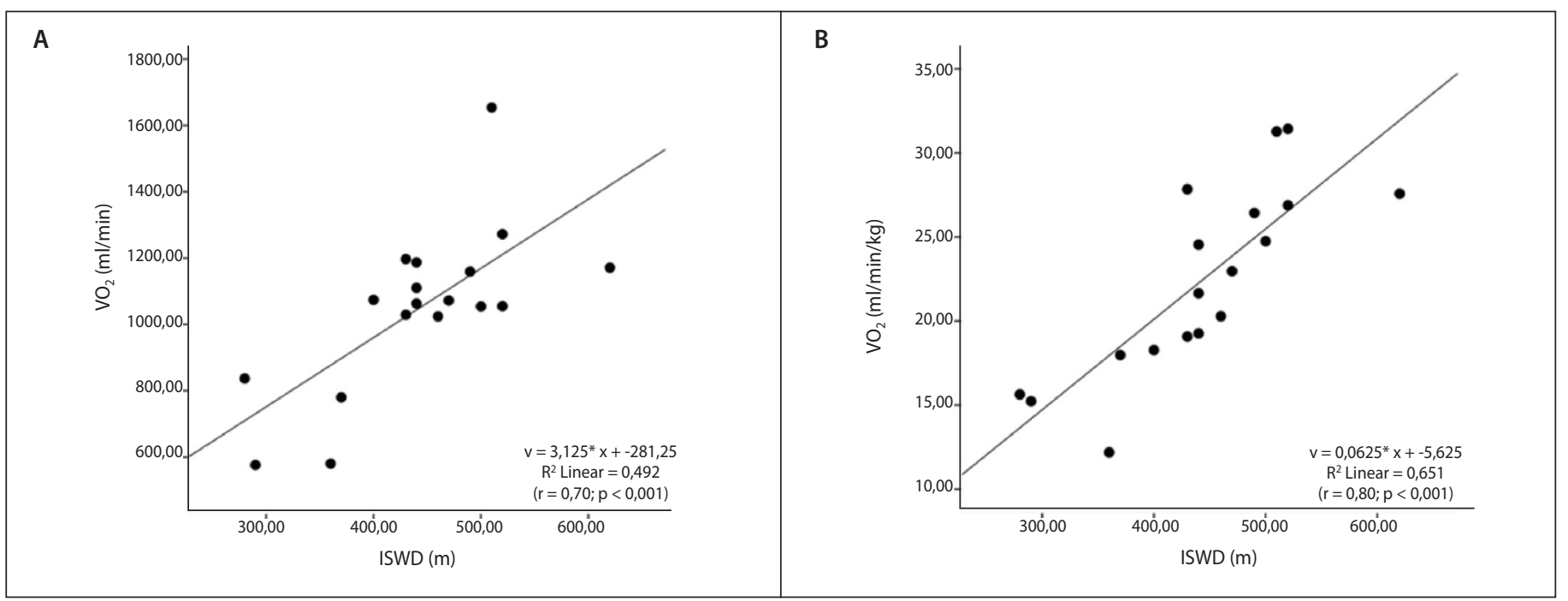

Figure 1. Significant correlations between oxygen consumption (A) and oxygen consumption corrected by the body (B) with the distance on the Incremental Shuttle Walk Test.

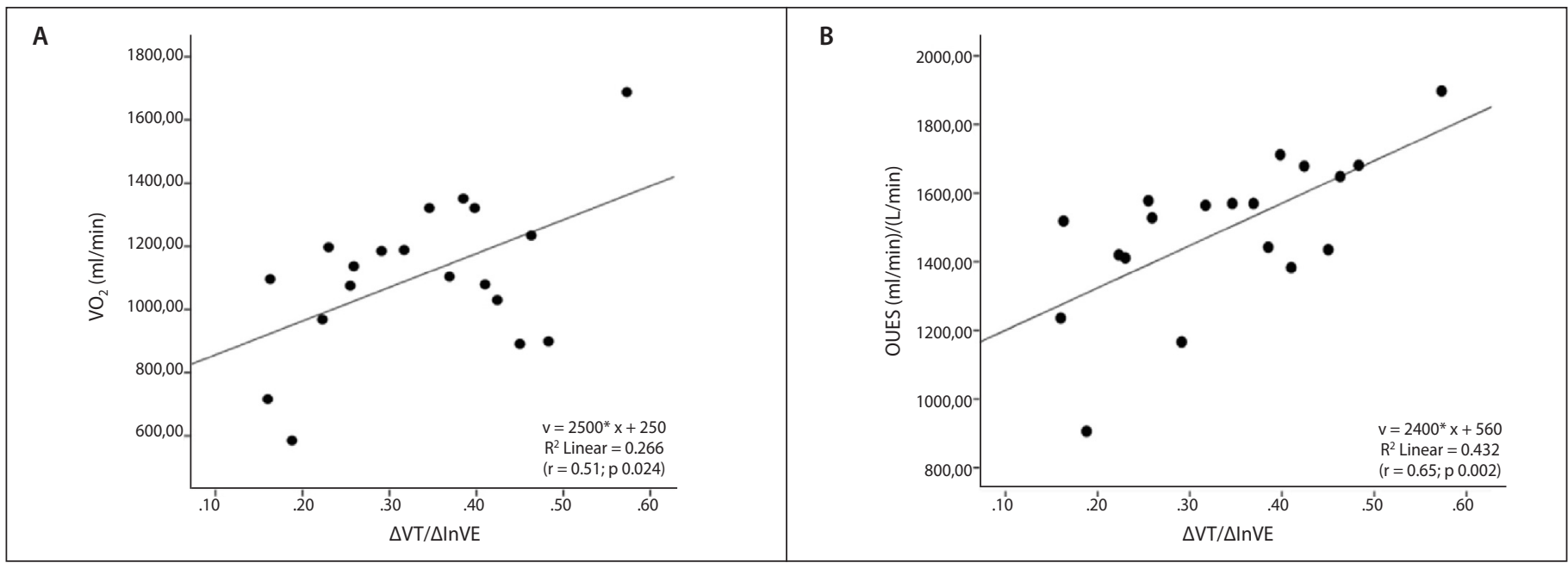

Figure 2. Significant correlations between oxygen consumption (A) and Oxygen Uptake Efficiency Slope (B) with the linearized ventilatory pattern ( $\Delta V T / \Delta I n V E)$.

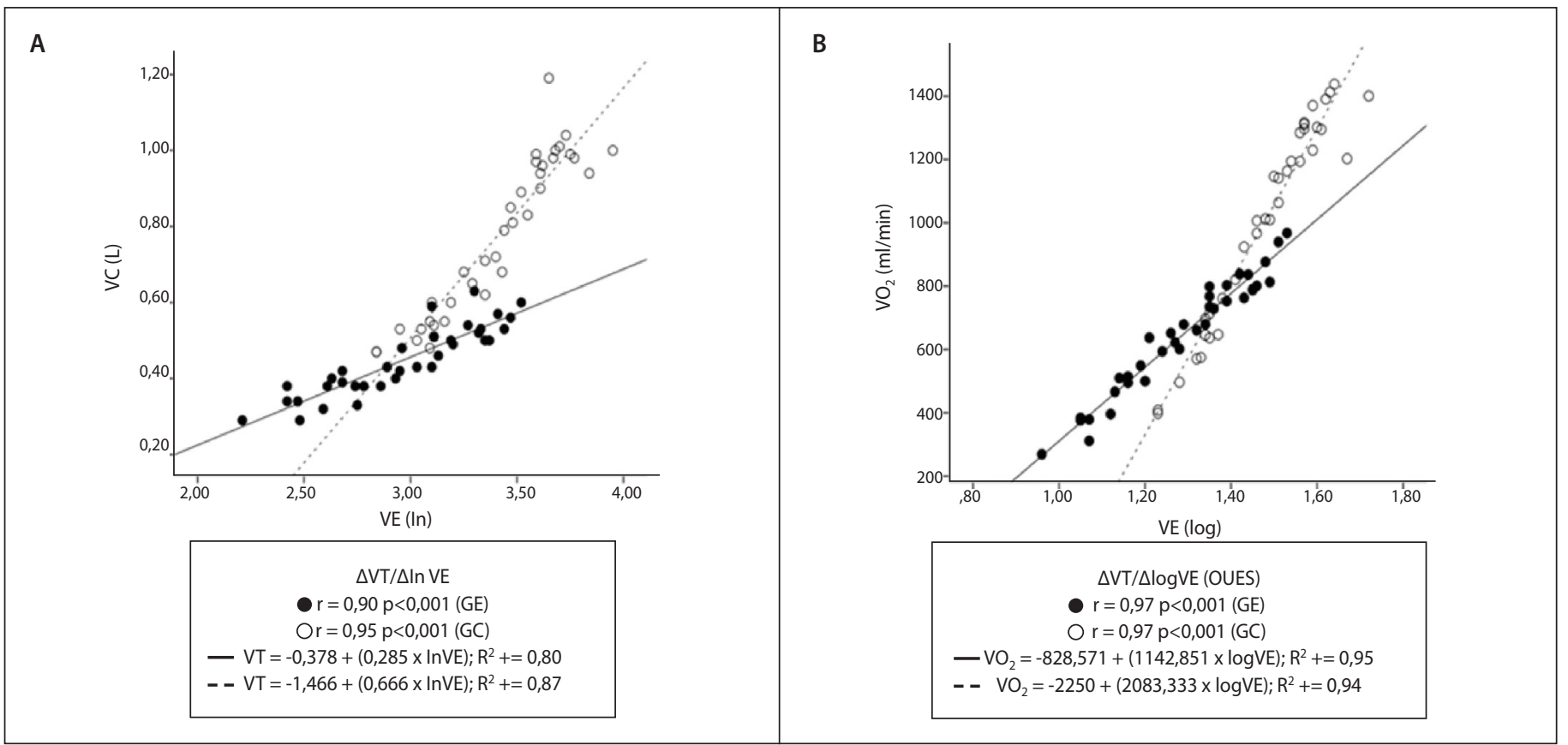

Figure 3. Typical examples of curves observed in patients with AIS. Graph comparing data from one patient with AIS (SG) in the late postoperative period (14 years) and one healthy individual from the control group (CG) (15 years). A: breathing pattern during the Incremental Shuttle Walk Test, measured by linear regressions between tidal volume (VT) and minute volume (VE) linearized by natural logarithm. B: Oxygen Uptake Efficiency Slope (OUES) evaluated by linear regressions, from the logarithmic relation between oxygen consumption $\left(\mathrm{VO}_{2}\right)$ and VE. Graphical representations show a flatter slope in SG compared to the CG. The magnitude of the slope appears in bold in the equation. 
independent and submaximal cardiorespiratory reserve variable, without the need for maximum effort, reliable in children, adolescents and adults. ${ }^{23}$ The evaluation of OUES in submaximal tests such as ISWT becomes an important tool to identify the limitation of exercise capacity. This fact can be confirmed in our study, because, even with reduced ISWD, we observed a significant reduction of OUES in the SG and correlation with the ventilatory pattern. In addition, we observed a significant slope flattening of the curve in the OUES graph in our results. Although there is evidence in our study of physical deconditioning in SG, we believe that pulmonary function and respiratory mechanics can play an important role in the reduced exercise capacity found. The lower values of VT, VE and $\triangle V T / \triangle I n V E$ found in our study suggest a restrictive ventilatory pattern during exercise in AIS patients. Even though the RR was not different between the groups, the RR reached at the end of ISWT in SG occurred with lower VT values when compared to CG. Therefore, we believe that the restrictive respiratory pattern during walking and physical deconditioning in SG were crucial for the reduced ISWD and exercise capacity.

The increase in respiratory work seems to be present in the scoliosis patients at the late postoperative period, since the patients presented worse respiratory pattern, represented by the worse relation $\triangle V T / \Delta I n V E$, showing an important flattening of the curve in our results. In addition, we observed a moderate correlation between the ventilatory pattern and the OUES, indicating that oxygen uptake during exercise is lower when there is a worse respiratory pattern. We suggest that the worse respiratory pattern contributes to the physical deconditioning, independent of the surgical correction. The correlations with OUES reinforce the influence of the respiratory pattern on exercise capacity. Beyond the worse ventilatory pattern in the SG, we found significantly higher ventilatory reserve (VR) values, reinforcing the presence of physical deconditioning. ${ }^{20}$ The negative correlation between $\mathrm{VO}_{2}$ and ISWD with VR, found in our study, shows that a better performance is observed when VR is lower. As the scoliosis patients at the LPO presented higher VR values, we suggested that ventilatory limitation may be the cause or contribute to exercise intolerance. ${ }^{24}$

Although restrictive ventilatory disorders are described as frequent in AIS patients, ${ }^{25}$ especially in curvatures greater than $45^{0,5}$, we observed that even with slight residual curvatures after the surgical procedure,

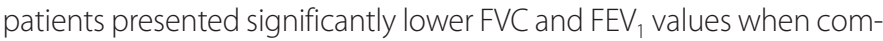
pared to the CG. Studies have found increased pulmonary function
(FVC and FEV ) two years after the surgical procedure in AIS patients. ${ }^{26}$ However, its effects are still controversial, it is not clear if lung function improves or worsens after the surgical procedure. ${ }^{27}$

For reasons that are still unknown, patients with scoliosis may be less physically active than those of the same sex and age. The exercise capacity seems to be reduced in the preoperative phase ${ }^{3,7}$ and we observed in our study that this reduction is also observed two years after the surgical procedure. Considering that exercise capacity may be reduced even in patients with mild and moderate scoliosis, other factors may influence this variablemay be due to the low adherence of individuals to the practice of physical activity. ${ }^{28}$

The reduced participation of AIS individual in physical activities may be related to some constraint on their appearance, reducing the willingness to participate in aerobic activities. ${ }^{29}$ However, our data demonstrate that correcting deformity does not seem to be synonymous with better exercise capacity and that a sedentary lifestyle is likely to be maintained.

Among the limitations of the study, we can mention the non-performance of CPET and the absence of objective assessment of daily physical activity level. However, it is worth mentioning that the ISWT was able to identify a reduction of exercise capacity in this sample and the data suggest the presence of physical deconditioning. In addition, this is the first study known by the authors using ISWT in AIS patients at the late postoperative period and reinforces the need to include these patients in physical activity programs.

Further studies that correlate the daily physical activity level and aerobic training with exercise capacity in individuals with AIS are necessary since the cause of exercise limitation in this population has not yet been elucidated and may be a consequence of physical deconditioning

\section{CONCLUSIONS}

Patients with AIS after two years of surgery present a significant exercise capacity reduction associated to a reduced pulmonary function and residual spinal curvature. The ISWT was capable to assess the exercise capacity in this population and showed that AIS patients present a compromised ventilatory pattern during walking.

All authors declare no potential conflict of interest related to this article

AUTHORS' CONTRIBUTIONS: Each author made significant individual contributions to this manuscript. GSA (0000-0002-0554-6358)* was the main contributor in the drafting of the manuscript, performed all assessments described in Methods, and participated in the entire scientific research process. BMAS (0000-0002-9539-5089)*, EFS (0000-0002-8580458X)*, MTF (0000-0002-2266-708X)* and JMF (0000-0001-9929-0420)* carried out the evaluations together with the main author, organized the data, carried out the initial statistical analyses. AOG (0000-0003-3143-2845)* surgeries and follow-up of the volunteers in the late postoperative period. LYY (0000-0002-2790-0266)* evaluated the data of the statistical analysis and handled the reading and critical review of the paper. VZD (0000-0002-6222-3555)* and MCV (0000-0003-2879-6541)* statistical analysis and intellectual concept of the article and preparation of the entire research project. *ORCID (Open Researcher and Contributor ID).

\section{REFERENCES}

1. Cheng JC, Castelein RM, Chu WC, Danielsson AJ, Dobbs MB, Grivas TB, et al. Adolescent idiopathic scoliosis. Nat Rev Dis Prim. 2015;1:15030.

2. Sánchez-Márquez JM, Fernández-Baillo N, Garcia-Fernández A, Quintáns J, Pérez-Grueso FJ. Effect of thoracoplasty on pulmonary function and esthetics in patients with adolescent idiopathic scoliosis. Rev Esp Cir Ortop Traumatol. 2010;54(3):156-61.

3. Saraiva BMA, Araujo GS, Sperandio EF, Gotfryd AO, Dourado VZ, Vidotto MC. Impact of Scoliosis Severity on Functional Capacity in Patients With Adolescent Idiopathic Scoliosis. Pediatr Exerc Sci. 2018;30(2):243-50.

4. Lenke LG, White DK, Kemp JS, Bridwell KH, Blanke KM, Engsberg JR. Evaluation of ventilatory efficiency during exercise in patients with idiopathic scoliosis undergoing spinal fusion. Spine (Phila Pa 1976). 2002;27(18):2041-5

5. Barrios C, Pérez-Encinas C, Maruenda Jl, Laguía M. Significant ventilatory functional restriction in adolescents with mild or moderate scoliosis during maximal exercise tolerance test. Spine (Phila Pa 1976). 2005;30(14):1610-5.

6. Martínez-Llorens J, Ramírez M, Colomina MJ, Bagó J, Molina A, Cáceres E, et al. Muscle dysfunction and exercise limitation in adolescent idiopathic scoliosis. Eur Respir J. 2010;36(2):393-400.
7. Sperandio EF, Alexandre AS, Yi LC, Poletto PR, Gotfryd AO, Vidotto MC, et al. Functional aerobic exercise capacity limitation in adolescent idiopathic scoliosis. Spine J. 2014;14(10):2366-72.

8. Sperandio EF, Vidotto MC, Alexandre AS, Yi LC, Gotfryd AO, Dourado VZ. Exercise capacity, lung function and chest wall shape in patients with adolescent idiopathic scoliosis. Fisioter Mov. 2015;185(3):563-72.

9. Singh SJ, Morgan MD, Scott S, Walters D, Hardman AE. Development of a shuttle walking test of disability in patients with chronic airways obstruction. Thorax. 1992;47(12):1019-24.

10. Hill K, Dolmage TE, Woon L, Coutts D, Goldstein R, Brooks D. A simple method to derive speed for the endurance shuttle walk test. Respir Med. 2012;106(12):1665-70.

11. Lanza FDC, Zagatto EDP, Silva JC, Selman JP, Imperatori TB, Zanatta DJ, et al. Reference Equation for the Incremental Shuttle Walk Test in Children and Adolescents. J Pediatr. 2015;167(5):1057-61.

12. Singh SJ, Morgan MDL, Hardman AE, Rowe C, Bardsley PA. Comparison of oxygen uptake during a conventional treadmill test and the shuttle walking test in chronic airflow limitation. Eur Respir J. 1994;7(11):2016-20

13. Haskell WL, Lee IM, Pate RR, Powell KE, Blair SN, Franklin BA, et al. Physical activity and public health: Updated recommendation for adults from the American College of Sports Medicine and the American Heart Association. Med Sci Sports Exerc. 2007:39(8):1423-34. 
14. Fairbank JCT. William Adams and the Spine of Gideon Algenon Mantell. Ann R Coll Surg Engl. 2004;86(5):1953-5.

15. Pereira CAC. Espirometria. J Bras Pneumol. 1996;28(Suppl 3):S1-82.

16. Pereira CAC, Lemle A, Algranti E, Jansen JM, Valença LM, Nery LE, et al. I Consenso Bras sobre Espirometria J Pneumol. 1996;28:S1-82.

17. Dourado VZ, Tanni SE, Godoy I. Valores de referência para o teste de caminhada com carga progressiva em indivíduos saudáveis: da distância percorrida às respostas fisiológicas. J Bras Pneumol. 2013;39(2):190-7.

18. Alves VLDS, Avanzi O. Objective assessment of the cardiorespiratory function of adolescents with idiopathic scoliosis through the six-minute walk test. Spine (Phila Pa 1976). 2009;34(25):E926-9.

19. Singh SJ, Jones PW, Evans R, Morgan MDL. Minimum clinically important improvement for the incremental shuttle walking test. Thorax. 2008;63(9):775-7.

20. Wasserman K, Hansen JEH, Sue DY, Stringer WW, Sietsema KES, Sun X-G. Principles of Exercise Testing and Interpretation: Including Pathophysiology and Clinical Applications. 50th ed. Philadelphia, PA: Lippincott Wiliams \& Wilkins; 2012

21. Baraldi E, Carraro S. Exercise testing and chronic lung diseases in children. Paediatr Respir Rev. 2006;7(suppl. 1):S196-8.

22. Rosa FWF, Camelier A, Mayer A, Jardim JR. Evaluating physical capacity in patients with chronic obstructive pulmonary disease: comparing the shuttle walk test with the encouraged 6-minute walk test. J Bras Pneumol. 2006:32(2):106-13.
23. Williamson W, Fuld J, Westgate K, Sylvester K, Ekelund U, Brage S. Validity of reporting oxygen uptake efficiency slope from submaximal exercise using respiratory exchange ratio as secondary criterion. Pulm Med. 2012;2012.

24. Lorente A, Barrios C, Burgos J, Hevia E, Fernández-Pinea L, Lorente R, et al. Cardiorespiratory Function Does Not Improve 2 Years after Posterior Surgical Correction of Adolescent Idiopathic Scoliosis. Spine (Phila Pa 1976). 2017;42(18):1391-7.

25. Trevisan ME, Osório L, Portela C, Zenir E, Moraes C De. Ergoespirometria em indivíduos com escoliose idiopática Ergospirometry in individuals with idiopathic scoliosis. Fisioter Pesqui. 2010;17(2):136-40.

26. Lee AC, Feger MA, Singla A, Abel MF. Effect of Surgical Approach on Pulmonary Function in Adolescent Idiopathic Scoliosis Patients: A Systemic Review and Meta-Analysis. Spine. 2016;41(22).

27. Kim YJ, Lenke LG, Bridwell KH, Auerbach JD, Sides BA. Pulmonary Function in Adolescent Idiopathic Scoliosis Relative to the Surgical Procedure. Spine (Phila Pa 1976). 2011;36(20):1665-72.

28. Negrini S, Donzelli S, Aulisa AG, Czaprowski D, Schreiber S, de Mauroy JC, et al. 2016 SOSORT Guidelines: Orthopaedic and Rehabilitation Treatment of Idiopathic Scoliosis during Growth. Scoliosis Spinal Disord. 2018;13:3.

29. Kesten S, Garfinkel SK, Wright T, Rebuck AS. Impaired Exercise Capacity in Adults Whith Moderate Scoliosis. Chest. 1991;3(99):663-6. 